Review Article

\title{
HDAC Inhibitors as Epigenetic Regulators of the Immune System: Impacts on Cancer Therapy and Inflammatory Diseases
}

\author{
Elizabeth E. Hull, ${ }^{1}$ McKale R. Montgomery, ${ }^{1}$ and Kathryn J. Leyva ${ }^{2}$ \\ ${ }^{1}$ Biomedical Sciences Program, Midwestern University, 19555 N 59th Avenue, Glendale, AZ 85308, USA \\ ${ }^{2}$ Department of Microbiology \& Immunology, Arizona College of Osteopathic Medicine, Midwestern University, 19555 N 59 th Avenue, \\ Glendale, AZ 85308, USA
}

Correspondence should be addressed to Elizabeth E. Hull; ehullx@midwestern.edu

Received 20 February 2016; Revised 8 June 2016; Accepted 29 June 2016

Academic Editor: Masahiko Hatano

Copyright (C) 2016 Elizabeth E. Hull et al. This is an open access article distributed under the Creative Commons Attribution License, which permits unrestricted use, distribution, and reproduction in any medium, provided the original work is properly cited.

\begin{abstract}
Histone deacetylase (HDAC) inhibitors are powerful epigenetic regulators that have enormous therapeutic potential and have pleiotropic effects at the cellular and systemic levels. To date, HDAC inhibitors are used clinically for a wide variety of disorders ranging from hematopoietic malignancies to psychiatric disorders, are known to have anti-inflammatory properties, and are in clinical trials for several other diseases. In addition to influencing gene expression, HDAC enzymes also function as part of large, multisubunit complexes which have many nonhistone targets, alter signaling at the cellular and systemic levels, and result in divergent and cell-type specific effects. Thus, the effects of HDAC inhibitor treatment are too intricate to completely understand with current knowledge but the ability of HDAC inhibitors to modulate the immune system presents intriguing therapeutic possibilities. This review will explore the complexity of HDAC inhibitor treatment at the cellular and systemic levels and suggest strategies for effective use of HDAC inhibitors in biomedical research, focusing on the ability of HDAC inhibitors to modulate the immune system. The possibility of combining the documented anticancer effects and newly emerging immunomodulatory effects of HDAC inhibitors represents a promising new combinatorial therapeutic approach for HDAC inhibitor treatments.
\end{abstract}

\section{Introduction}

Within a eukaryotic cell, DNA associates with histone and nonhistone proteins to form chromatin. The degree to which DNA is wound around histone proteins affects transcription: the more tightly wounded the DNA, the more condensed the DNA, and gene expression is repressed. The N-terminal regions of histone proteins are substrates for a variety of enzymes that result in posttranslational modifications of histone proteins, including phosphorylation, methylation, ubiquitination, and acetylation. Combined, these posttranslational modifications epigenetically regulate the extent of gene transcription. Of these known epigenetic factors, histone acetylation has garnered much attention in the last decade as one widely recognized factor regulating gene expression. Acetylation of histone proteins is a balance between the activities of both histone acetyltransferases (HATs) and HDACs with histone acetylation being generally associated with an increase in gene transcription while deacetylation results in decreased gene transcription.

Although it is eminently comprehensible, this simplified view leads to a vast underestimate of the effects of HDAC inhibitor treatment on chromatin structure. HDAC inhibitor treatment rapidly leads to compensating changes in histone methylation and changes in expression of histone modulators so that the effects of HDAC inhibitor treatment, even at the level of chromatin structure, are not fully delineated. In addition, as the majority of acetylation occurs on nonhistone proteins, the consequences of inhibiting HDACs using available HDAC inhibitors have profound effects on many processes independent of chromatin structure. HDAC inhibitor treatment alters gene expression at many levels 
including transcription factor activity, miRNA expression, and signal transduction pathways. While the most commonly reported effect of HDAC inhibitors on tumor cells is as an inducer of apoptosis, they have also been shown to interfere with cellular growth [1-3] and differentiation $[2,4]$ and to inhibit angiogenesis [5, 6]. In addition, HDAC inhibitors have been shown to modulate immune responses which, in turn, affect many diverse cellular functions and thus may help to explain the basis of the clinical utility of HDAC inhibitors. To harness the full potential of HDAC inhibitors, a more complete understanding of the role of acetylation on signaling at the cellular and systemic levels is required.

It is exciting that the clinical utility of HDAC inhibitors has been extended far beyond treatments for cancer, as they have now been investigated for their therapeutic potential in all top 10 leading causes of death in the US. For example, valproic acid has been used for decades for the treatment of depressive disorders with the intent to prevent suicidal behaviors (number 10 on the list) [7, 8]. More recently, HDAC inhibitors have begun to be investigated for their potential to improve outcomes following spinal cord injury, a common consequence of accidental injury (number 4 on the list) [9, 10]. In this regard, the efficacy of HDAC inhibitors appears to be contingent on their very potent anti-inflammatory actions. Indeed, the etiologies and complications which contribute to the remaining primary causes of death (heart disease, cancer, lower respiratory disease, stroke, Alzheimer's disease, diabetes, influenza and pneumonia, and kidney disease) are also inflammatory-mediated, and so discussion of HDAC inhibitors and their therapeutic, anti-inflammatory capacities is warranted.

In this review, we focus on the use of HDAC inhibitors in basic biomedical research and their impact on the immune system for several reasons. First, although four HDAC inhibitors are currently FDA-approved for the treatment of hematological malignancies, clinical trials using HDAC inhibitors against other cancers, particularly solid tumors, have failed. Our premise is that a greater understanding of the complex effects of these inhibitors on HDAC activities and cellular immunomodulatory processes is necessary in order to aid in the design of the next generation of these important drugs. Second, a more complete knowledge of HDAC enzymes and inhibitors is likely to reveal additional, still unrecognized, cellular processes which could potentially impact the pathophysiology of disease processes and must be taken into account in experimental design and in data analysis and interpretation. Finally, already proven clinically useful as anticancer treatments, HDAC inhibitors have a newly delineated role in modulating the activity of the immune system. Given the emerging importance of immunotherapy in cancer treatment, HDAC inhibitors may be useful in the development of new anticancer therapeutic strategies, including combination therapy. This review will summarize what is known about the cellular and systemic effects of HDAC inhibitors, with special emphasis as to how they relate to the immune system. But in order to achieve their full therapeutic potential, HDAC inhibitors need to be understood at all levels.

\section{Histone Deacetylase (HDAC) Enzymes}

2.1. Overview. Currently, 18 HDAC enzymes have been identified in mammalian cells, which are subdivided into four main classes based on their homology to yeast HDACs. Three of the four classes (Classes I, II, and IV) are zinc-dependent enzymes while Class III HDACs are $\mathrm{NAD}^{+}$-dependent. Class I HDACs, consisting of HDAC1, HDAC2, HDAC3, and HDAC8, are ubiquitously expressed in the nucleus in all tissues and are homologous to the yeast HDAC RDP3. HDAC1 and HDAC2 are primarily nuclear while HDAC3 and HDAC8 can shuttle in and out of the nucleus [11] and many substrates including tumor suppressors, steroid receptors, and transcription factors have been identified as substrates which are deaceylated by Class I HDACs. Class II HDACs share homology with the yeast HDAC HDA1, are associated with tissue specific functions, and deacetylate many nonhistone proteins. Class II HDACs are subdivided into Class IIA, consisting of HDAC4, HDAC5, HDAC7, and HDAC9, and Class IIB, which consists of HDAC6 and HDAC10. Class IIA HDACs show both nuclear and cytosolic localization, shuttling between these two compartments in response to different signals [11, 12]. Class IIB HDACs are localized mainly in the cytoplasm and appear to function as regulators of signal transduction and motility, as these HDACs deacetylate cortactin, Hsp90, and tubulin [1]. HDAC11 is the only member of Class IV HDACs and is homologous with Class I and Class II enzymes. Little is known about HDAC11, but expression has been noted in the kidney, brain, testes, heart, and skeletal muscle (reviewed in [13]) and has been shown to regulate oligodendrocyte development [14] and expression of interleukin-10 by antigen-presenting cells (APCs) [15]. Class III HDACs, also called sirtuins, consisting of SIRT $1-7$, are homologous with the yeast sirtuin protein Sir2 (reviewed in [13]). Sirtuins are widely expressed in human tissues and regulate a variety of biological functions such as oxidative stress, DNA repair, metabolism, and aging $[16,17]$. The diversity of HDACs revealed by this classification scheme suggests that HDAC inhibitors are fundamental to the regulation of numerous and diverse biological processes.

2.2. HDAC Activities and Multisubunit Complexes. Histone deacetylases (HDACs) are a superfamily of enzymes originally named because they remove an acetyl group from $\varepsilon-\mathrm{N}$ acetyl lysine amino acid. Although the name HDAC implies some specificity for histones, HDACs deacetylate a wide range of nonhistone proteins (see [18-20] for a few examples) and are more appropriately termed lysine-specific protein deacetylases. These enzymes are important in the epigenetic regulation of gene expression and the control of cellular activities. It has increasingly become clear that acetylation status is a common posttranslational modification of both histone and nonhistone proteins, with 1,750 proteins (nuclear and cytosolic) identified as being regulated by posttranscriptional changes in acetylation to date [21]. In fact, phylogenetic studies have shown that histone proteins are not the primary substrates for HDACs [22], with other substrates being DNAbinding and DNA-repair proteins, transcription factors, signal transduction molecules, chaperone proteins [23-25], 
and proteins involved in cellular motility $[19,26]$ to name a few. The involvement of acetylation in a broad range of biological activities has led to intense interest in the biological roles of this posttranscriptional modification.

Understanding is further complicated by the varying interactions of HDACs with each other (e.g., associations between HDAC1, HDAC2, and HDAC3 $[27,28]$ ) and with large, multiprotein complexes (e.g., CoREST, NuRD, Sin3, and NCoR) which, by themselves, exhibit diverse and often cell-type specific functions. For example, the NuRD complex promotes gene silencing via chromatin remodeling, while the NCoR complex is a major corepressor for nuclear receptors. Thus, inhibition of a specific HDAC may have context dependent consequences on cellular functions. In addition, it is reasonable to expect that measured $\mathrm{IC}_{50}$ values might differ when HDAC enzymes form complexes in cells and it is certainly possible that even the specificities of the inhibitors might be altered.

\section{Histone Deacetylase (HDAC) Inhibitors}

3.1. Introduction to HDAC Inhibitors. Histone deacetylase (HDAC) inhibitors are a family of natural and synthetic compounds that differ in their target specificities and activities, both in the clinical setting and in laboratory studies [25]. HDAC inhibitors are broadly classified into four main groups based on their structure: hydroxamic acids, cyclic peptides, benzamides, and short-chain fatty acids. Three of the four FDA-approved anticancer HDAC inhibitors are hydroxamic acids (SAHA, belinostat, and panobinostat) and have been reported to be nonspecific HDAC inhibitors affecting all "classical" HDACs (Classes I, II, and IV). The fourth FDAapproved HDAC inhibitor, FK228, is a cyclic peptide and has been reported to be specific for Class I HDACs. Several other HDAC inhibitors have been tested in vitro or are in current clinical trials and have been recently reviewed elsewhere [25, 29-32]. While generalizations regarding target specificities are valuable as a starting point, we have found that the story is much more complex. As West and Johnstone [30] point out: “... reliable determination of HDAC inhibitor target specificity in vitro using standard assays with recombinant HDAC proteins has been hindered due to protein misfolding, lack of enzymatic activity, and most importantly, the inappropriate assessment of isolated HDACs that exist as multiprotein complexes in physiologic conditions."

\subsection{Limitation in the Characterization of HDAC Inhibitors.} Complete understanding of the activities of compounds in the clinical setting requires an understanding of the inhibitor effects at multiple levels, including the enzymes which may be targeted by the inhibitor, as assayed in vitro, in cell-based assays to determine cellular effects for broader impacts, and in animal/human studies to delineate any systemic effects revealed by preclinical and clinical trials. This portion of the review will consider the role of HDAC inhibitors at each of these levels.
3.2.1. In Vitro Assays of HDAC Inhibitors. In vitro assays, usually used to definitively ascertain the mode of action of an inhibitor, have proved problematic in the case of HDAC inhibitors as the values quoted between similar assays are extremely variable. For instance, Hu et al. [33] determined, using recombinant HDAC proteins, that trichostatin A (TSA) inhibits HDAC1, HDAC3, and HDAC8 with equal potency and has $\mathrm{IC}_{50}$ values of $0.1-0.3 \mu \mathrm{M}$. On the other hand, Khan et al. [11] report $\mathrm{IC}_{50}$ values in the nanomolar range, with TSA having lower efficacy towards HDAC8 by two orders of magnitude compared with HDAC1 and HDAC3. Similar differences were seen with MS-275 between the two studies. Although both studies expressed recombinant HDAC enzymes using the baculovirus expression system, they used different substrates. Hu et al. used purified, labeled histones while Khan et al. used a commercial fluorogenic peptide substrate. However, little difference between these two substrates was observed when HDAC enzymes purified from liver were used. Indeed, the $\mathrm{IC}_{50}$ values for TSA measured using isolated HDAC enzymes are similar and, more specifically, relatively similar $K_{m}$ and $V_{\max }$ values for each reaction have been reported for both purified histone and peptide substrates $[34,35]$. Although using HDAC enzymes purified from tissue may be deemed more physiological, these assays are unable to determine the specificity of an inhibitor. From these data, it is difficult to make conclusions as to which HDAC enzyme is targeted or what the $\mathrm{IC}_{50}$ values truly are for any given HDAC inhibitor as there are fundamental disagreements in the conclusions which can be drawn from each set of assays.

An alternate approach to determine specificity of HDAC inhibitors uses fluorescence resonance energy transfer (FRET) assays for measuring binding of an inhibitor to HDAC enzymes. FRET assays either directly measure the inhibitor-enzyme binding [36] or use a competition assay to measure the ability of an inhibitor to displace the compound from the active site of an experimental inhibitorenzyme pair. Although these assays do not address how the inhibitor affects enzyme activity, they provide definitive measurements of $K_{m}$ of inhibitor binding to each HDAC and identify possible off-target interactions. Interestingly, a similar variation in values was seen between the two assays. Marks et al. [36] report binding values of 1-10 $\mathrm{nM}$ for most HDAC-HDAC inhibitor pairs while Riester et al. [37] report values in the $300 \mathrm{nM}$ to $1.1 \mu \mathrm{M}$ range. Only values for SAHA were measured in both assays and the values for this inhibitor range from $1.8 \pm 0.3 \mathrm{nM}$ in the FRET binding to HDAC6 assay and $1.0 \mu \mathrm{M}$ using the reciprocal binding constant in the FRET competition assay [36]; these and other data are delineated in Table 1.

The aggregate conclusion from these studies is that the $\mathrm{IC}_{50}$ of HDAC inhibitors is dependent on enzyme preparation and is also assay dependent. Without a clear understanding of the enzyme targets and potency of HDAC inhibitors, interpretation of in vivo work becomes more difficult and the uncertainty in the specificity, targets, and efficacy of HDAC inhibitors from in vitro studies must frame the interpretation of in vivo assays. 


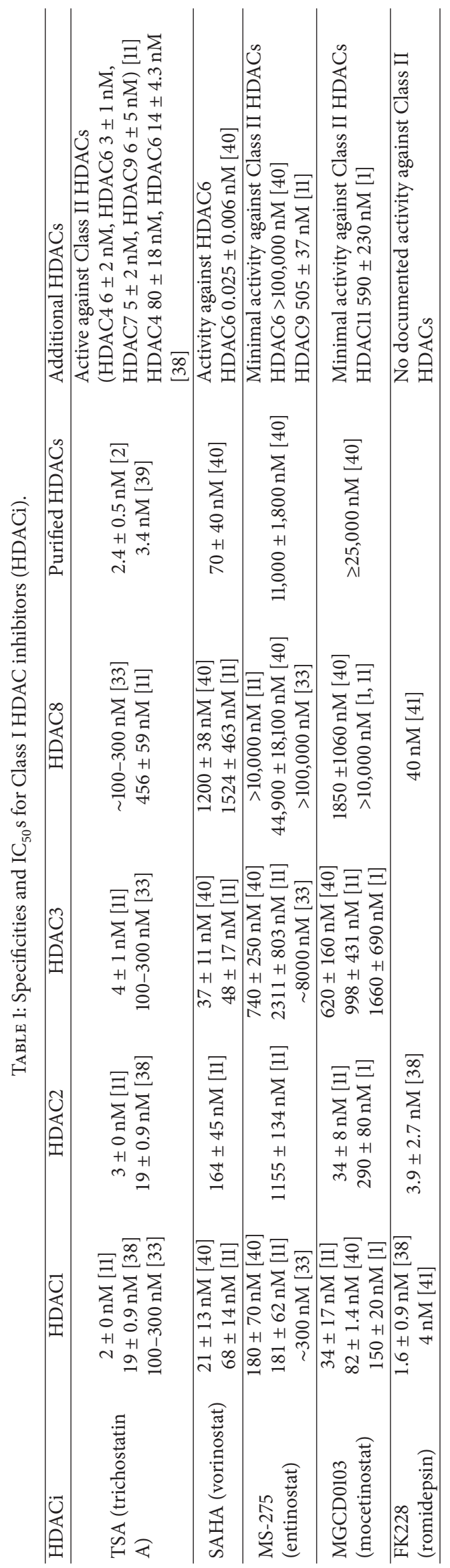


TABle 2: Assays to assess HDAC inhibitor effects.

\begin{tabular}{lc}
\hline Cell-based assays & References \\
\hline Apoptosis & {$[1,33,42-44]$} \\
Cell cycle arrest & {$[1,3,12,45,46]$} \\
Cytotoxicity & {$[40,41,47]$} \\
Differentiation & {$[2,4]$} \\
Gene expression & {$[1,3,33,40]$} \\
Growth arrest & {$[2,3,11]$} \\
Gene expression changes & {$[1,3,33,40]$} \\
Histone hyperacetylation & {$[1,3,12,39,40,47,48]$} \\
Inflammation & {$[48-50]$} \\
Motility & {$[1,19,26]$} \\
ROS induction & {$[43,51]$} \\
Senescence & {$[52-54]$} \\
Viability & {$[1,12,40]$} \\
\hline In vivo assays & References \\
\hline Antiangiogenesis & {$[5,6]$} \\
Drug seeking behavior & {$[55]$} \\
Oncogenesis & {$[1,40,56,57]$} \\
Senescence & {$[58]$} \\
Thermogenesis & {$[59]$} \\
\hline
\end{tabular}

3.2.2. Cell-Based Assays. Variation in the $\mathrm{IC}_{50}$ derived from in vivo and in vitro measurements is expected but this variability is exacerbated by the large number of cell-based assays used. As the effects of HDAC inhibition are wideranging, a variety of cell-based assays are needed to assess activity of HDACs (summarized in Table 2). Although these assays are not comparable and cannot reveal specificity, these assays have the advantage of being more biologically relevant and are better indicators of the downstream consequences of epigenetic reprogramming by HDAC inhibition.

Further investigation of HDAC inhibitor activity using cell-based assays is essential to understanding the activity of HDAC inhibitors in vivo. Acetylation affects the activity of a variety of nonhistone proteins and these proteins are involved in signaling and gene expression so that cellular assays of HDAC inhibitor function are essential. An apt example of this is FK228 which is FDA-approved for cutaneous T cell lymphoma. This natural product has been characterized as a relatively specific inhibitor of $\mathrm{HDAC1}$ and HDAC2 (with 1-3 orders of magnitude higher $\mathrm{IC}_{50}$ for other HDACs tested) [38] and has been shown to induce hyperacetylation of histone $\mathrm{H} 3$ after 3 hours and altered p21 gene expression and cell cycle arrest after 6 hours of treatment [3]. However, FK228 has been shown to directly inhibit phosphatidylinositol 3-kinase activity in in vitro [42] and in cell-based assays [60]. Cellular responses to FK228 treatment include induction of apoptosis [3], increased reactive oxygen species, decreased mitochondrial membrane potential, and activation of the unfolded protein response and stress-activated protein kinase/c-Jun Nterminal kinase pathway [43]. However, as HDAC inhibitors, such as FK228, can change gene expression within hours of treatment [42] due at least in part to modification of transcription factors [25], cellular effects of HDAC treatment are difficult to predict. Although there are some commonalities in the proteins affected by HDAC inhibitors (several HDAC inhibitors will affect levels of p21 to trigger apoptosis), the cellular targets of most HDAC inhibitors are varied and sometimes unexpected.

3.2.3. Multiple Targets for Most HDAC Inhibitors. Unfortunately, many commercially available HDAC inhibitors have not been sufficiently well characterized to support use in the manner for which they are marketed. For instance, depudecin is a natural product which was first identified as a compound that reversed transformation by the ras oncogene [61] but was later identified as an HDAC inhibitor [4]. Although this HDAC inhibitor is marketed as an HDACl inhibitor, depudecin has only been tested for activity against HDAC1 using an in vitro recombinant assay [4] so that its true target specificity profile has not been determined. Similarly, MC1293 is marketed as an HDAC1 inhibitor but a substrate independent FRET assay of inhibitor to protein binding suggests that this inhibitor binds to $\mathrm{HDACl}$ with low affinity while binding to HDAC6 with two orders of magnitude greater affinity [36].

Many in vitro assays of Class I HDAC inhibitors focus on histone targets and as Class I HDACs are localized to the nucleus, this seems to be a reasonable strategy. However, recent advances in mass spectrometry techniques have revealed that this ancient form of protein regulation is intimately linked to metabolism and that acetylation may affect gene expression at multiple levels (reviewed in [62]). The consequences of acetylation are far-reaching. For instance, acetylation changes the activity of transcription factors (e.g., p53, HIF1a, NF- $\kappa$ B, EKLF, E2F1, STAT1, GATA1/2/3, SrY, and MyoD) (reviewed in [25]). However, many consequences are downstream of transcription factors and are therefore more difficult to characterize. For instance, treatment with HDAC inhibitors changes histone methylation $[63,64]$, adding to the effect of acetylation on the binding of chromatin regulatory complexes (reviewed in [62]). Thus, much more characterization of the targets and consequences of acetylation must be completed.

3.3. Effects of HDAC Inhibitor Treatment. In highlighting the role of HDAC inhibitors as master epigenetic regulators, it is remarkable how cells treated with HDAC inhibitors are capable of self-regulation, ensuring that global changes are not lethal. Cells, and even entire organisms, can somehow tolerate extensive hyperacetylation of core histones and other proteins that occur following treatment. Recent work has demonstrated that cells respond to HDAC inhibitor treatment by rapidly increasing $\mathrm{H} 3 \mathrm{~K} 27 \mathrm{me} 3$ at the transcription start sites of genes capable of slowing growth, as well as minimizing protein hyperacetylation until gene expression patterns can be restored [65]. Once cells have adapted to survive this initial epigenetic disruption, HDAC inhibitors can further influence gene expression by other forms of epigenetic control, including indirectly impacting DNA and histone methylation, manipulating polycomb group proteins and proteins within the SWI/SNF complex, and regulating miRNA expression. Specific examples of how HDAC 
TABLE 3: Effects of acetylation of nonhistone proteins by HDAC inhibitors.

\begin{tabular}{|c|c|c|c|}
\hline Nonhistone proteins & Classification of protein & Function of acetylation & References \\
\hline \multirow{3}{*}{ p53 } & \multirow{3}{*}{ Tumor suppressor } & Increased DNA binding affinity & {$[66]$} \\
\hline & & Increased transcriptional activation & {$[66-68]$} \\
\hline & & Increased protein stability & {$[68,69]$} \\
\hline \multirow{2}{*}{ RUNX3 } & \multirow{2}{*}{ Tumor suppressor } & Increased transcriptional activation & [70] \\
\hline & & Increased protein stability & {$[70]$} \\
\hline \multirow{3}{*}{ STAT3 } & \multirow{3}{*}{ Signaling mediator } & Increased DNA binding affinity & {$[70-72]$} \\
\hline & & Increased transcriptional activation & {$[71,72]$} \\
\hline & & Promotes protein-protein interaction & {$[71,72]$} \\
\hline$\beta$-catenin & Signaling mediator & Promotes nuclear localization & {$[73]$} \\
\hline \multirow{3}{*}{ Estrogen receptor } & \multirow{3}{*}{ Steroid hormone receptor } & Increased transcriptional activation (basal) & [74] \\
\hline & & Decreased transcriptional activation (ligand dependent) & {$[74]$} \\
\hline & & Increased protein stability & {$[75]$} \\
\hline Myc & Transcription factor & Increased protein stability & {$[76,77]$} \\
\hline \multirow{2}{*}{ EKLF } & \multirow{2}{*}{ Transcription factor } & Promotes protein-protein interaction & {$[78]$} \\
\hline & & Increased transcriptional activation & [79] \\
\hline \multirow{3}{*}{ E2F1 } & \multirow{3}{*}{ Transcription factor } & Increased DNA binding affinity & {$[80,81]$} \\
\hline & & Increased transcriptional activation & {$[80,81]$} \\
\hline & & Increased protein stability & {$[80]$} \\
\hline \multirow{2}{*}{ GATA family } & \multirow{2}{*}{ Transcription factor } & Increased DNA binding affinity & {$[82,83]$} \\
\hline & & Increased transcriptional activation & {$[82-84]$} \\
\hline \multirow{2}{*}{ HIF- $1 \alpha$} & \multirow{2}{*}{ Transcription factor } & Decreased transcriptional activation & {$[85]$} \\
\hline & & Decreased protein stability & [85] \\
\hline \multirow{2}{*}{ MyoD } & \multirow{2}{*}{ Transcription factor } & Increased DNA binding affinity & {$[86]$} \\
\hline & & Increased transcriptional activation & {$[86-88]$} \\
\hline $\mathrm{NF}-\kappa \mathrm{B}$ & Transcription factor & Disrupts protein-protein interaction & [89] \\
\hline Foxp3 & Transcription factor & Increased stability & {$[90]$} \\
\hline
\end{tabular}

inhibitors can epigenetically regulate gene expression to influence desirable cellular outcomes are described below and summarized in Table 3.

3.3.1. Gene Expression. Regulation of histone acetylation by the activity of histone acetylases and histone deacetylases is a fundamental step in the epigenetic control of gene expression. Surprisingly, in spite of this seemingly generic global control of gene expression, only about $5-10 \%$ of gene transcription has been shown to be influenced by HDAC inhibitor treatment, with approximately half of the affected genes being upregulated and half being downregulated. However, HDAC inhibitors also mediate changes in gene expression via a direct effect on the activity of transcription factors and on multiple modes of epigenetic control; it is this level of reversible epigenetic regulation that makes HDAC inhibitors attractive and potentially effective manipulators of cellular and immunological outcomes.

Understanding the pleiotropic effects of HDAC inhibitors at the cellular level is complicated by the fact that HDACs can form complexes. Intriguingly, though SAHA and BML-210 are described as pan-HDAC inhibitors, the aminobenzamide BML-210 demonstrates a higher selectivity for the HDAC3NCoR complex than its hydroxymate counterpart, which demonstrated higher levels of selectivity for HDAC1 and
HDAC2 [48]. This work also demonstrated that aminobenzamides have a much smaller effect on the Sin3 protein complex than HDAC1/HDAC2 containing CoREST and NuRD complexes. Recently, these relationships between HDAC inhibitors and cellular complexes have been elegantly mapped by Bantscheff et al. [48]. Clearly, the cellular activity of each HDAC inhibitor is more complex and cannot be predicted from knowledge of the HDAC to which it binds.

Preventing or reducing transcription factor deacetylation represents another mechanism by which HDAC inhibitors have been shown to influence gene expression. For example, HDAC inhibitor-promoted acetylation stimulates the DNAbinding activity of $\mathrm{p} 53$, resulting in enhanced proapoptotic gene transcription [66]. Conversely, HDAC inhibition decreases angiogenic gene expression by decreasing HIF- $1 \alpha$ stability and transcriptional activity [5]. Notably, nonhistone protein acetylation can also influence protein stability, localization, and enzymatic activity, as well as interaction with other proteins.

\subsubsection{HDAC Inhibitors as Epigenetic Regulators}

(1) Chromatin Remodeling Enzymes. HDAC inhibitor treatment results in differential expression of epigenetic regulators such as chromatin remodeling enzymes. For example, 
enhancer of zeste homolog 2 (EZH2), a component of the polycomb-repressive complex involved in gene silencing and $\mathrm{H} 3 \mathrm{~K} 27 \mathrm{me} 3$, is increased in aggressive tumors, but it is inhibited by HDAC inhibitor treatment [91]. Decreased EZH2 expression results in the demethylation, and subsequent reexpression, of E-cadherin, which is associated with a much less aggressive cancer phenotype [91]. Similarly, HDAC inhibitors have been proven to be effective in restoring the expression of the mutually exclusive, catalytically active subunits of the SWI/SNF complex, BRM and BRG1, which are silenced in nearly $20 \%$ of all cancers [92-94]. However, the therapeutic utility of restoring $B R M$ and $B R G 1$ expression via HDAC inhibition is still in question as in vitro work has demonstrated that while reexpression of these proteins does slow cancer cell growth, it also promotes metastatic traits [63].

(2) Methylation. HDAC inhibitor treatment leads to a rapid change in histone and DNA methylation. In pulmonary fibroblasts, hypermethylation of the Thy-1 promoter region results in decreased Thy-1 expression and enhanced fibrosis. Treatment of Thy-1 (-) rat fibroblasts with the HDAC inhibitor TSA significantly decreased DNA methylation while coordinately increasing $\mathrm{H} 3 \mathrm{~K} 4 \mathrm{me} 3$ in the promoter region of Thy-1, resulting in restored Thy-1 expression [95]. However, in skeletal muscle fibroblast cells obtained from patients with Huntington's disease, HDAC inhibitor treatment resulted in differential effects on DNA methylation status, with $\sim 62 \%$ of all promoter regions assessed becoming demethylated, while $48 \%$ had increased methylation [96]. Following up on this work in vivo using mice with Huntington's disease phenotype, the researchers also observed that these changes in methylation status were associated with improved motor function and cognition in mice treated with an HDAC inhibitor compared to mice treated with a vehicle control [96].

(3) miRNA. The regulation, and dysregulation, of miRNA in human health and disease also demonstrates the utility of HDAC inhibitors in the epigenetic control of cellular gene expression as miRNA expression is also altered by HDAC inhibitor treatment. miRNAs are small noncoding RNA molecules that posttranscriptionally repress target gene expression. HDAC inhibition can rapidly alter miRNA levels and in turn indirectly mediate miRNA target gene expression. For example, treatment of breast cancer cells with a combination of sodium butyrate and panobinostat increased the expression of miR-31 which was accompanied by a subsequent repression of its target protein BIM1 that resulted in the induction of cellular senescence [52]. A study investigating the effects of HDAC inhibitors in hematopoietic malignancies revealed that HDAC inhibition relieves Myc-mediated transcriptional repression of the miR-15 and let-7 miRNA families, allowing for cells to downregulate the expression of the antiapoptotic genes $\mathrm{Bcl}-2$ and $\mathrm{Bcl}-\mathrm{xL}$ and, thus, induce apoptosis [44].

HDAC inhibitors also have the potential to decrease miRNA abundance on a much broader scale as HDAC1 has been shown to enhance miRNA processing by acetylating
TABlE 4: Changes in expression of immune-related genes in response to HDAC inhibition.

\begin{tabular}{lc}
\hline MCP1 (monocyte chemotactic protein 1) & {$[105]$} \\
MIP-1a (macrophage inflammatory protein 1a) & {$[105]$} \\
CD154 & {$[106,107]$} \\
IFN- $\gamma$ & {$[49,106,107]$} \\
NF- $\kappa$ B & {$[103]$} \\
NKG2D & {$[108,109]$} \\
PD-L1 & {$[110]$} \\
MHC & {$[103,111-114]$} \\
IL-10 & {$[106,107,115-117]$} \\
Antigen processing proteins & {$[113,118]$} \\
IL-1 $\beta$ & {$[49,115]$} \\
IL-6 & {$[115]$} \\
IL-12 & {$[49]$} \\
TNF- $\alpha$ & {$[49]$} \\
\hline
\end{tabular}

the miRNA processing protein DGCR8, which increases the production of mature miRNA species [97]. However, not all HDACs have this same effect, and some miRNAs appear to be more responsive than others [97]. Notably, several HDACs are also targeted by miRNA, which means that miRNAs also have the capacity to act as HDAC inhibitors. For example, miR-449a regulates prostate cancer cell growth and viability in part by targeting and repressing HDAC1 [98]. In hepatocellular carcinoma, overexpression of miR-221 has been proposed to result in the chronic inactivation of its tumor-suppressor target, HDAC6, thereby promoting liver tumorigenesis [99]. These are just a few examples of HDACmediated epigenetic regulation that highlight the potential power of using HDAC inhibitors for therapeutic purposes, but harnessing this potential will be hampered until we can truly understand how they work.

3.4. Summary of HDAC Inhibitors and Gene Expression. The first clinical success regarding use of HDAC inhibitors was seen in the treatment of certain forms of cancer, most notably cutaneous and peripheral $\mathrm{T}$ cell lymphomas. Development of these Class I-specific HDAC inhibitors focused on their ability to change gene expression, which subsequently led to inhibition of cell growth and apoptosis. This early success was not recapitulated in clinical trials using HDAC inhibitors for the treatment of solid tumors [100-102] which helped in leading to the refocusing of attention to the role of HDAC inhibitors as epigenetic modifiers. However, the dichotomy between liquid and solid tumors highlights the question of why hematopoietic tumor cells appear to be more susceptible to HDAC inhibition than normal cells but there is no shown efficacy of HDAC inhibitors against solid tumors. The answer as to why is unknown but may be related to cellular differences in the epigenomic changes in acetylation patterns that may alter the balance of pro- versus antiapoptotic protein expression [30], changes in transcription factor activity [90, $103,104]$, or change in the expression of immunomodulatory proteins (see Table 4). 


\section{Impact of HDAC Inhibition on the Immune System}

As delineated above, HDAC inhibitor treatment leads to diverse effects via multiple mechanisms to influence pathways which affect immune function. In aggregate, these signals may result in modulation of immune function and impact the role of the immune system in a variety of diseases, including cancer. Knowing that many of the underlying immune mechanisms that are activated to fight tumor cells are also important in regulating immune responses, it comes as no surprise that HDAC inhibitors have been studied for their utility in treating chronic inflammatory disorders [119].

4.1. Direct Impacts of HDAC Inhibitors on the Immune System. Early studies examining the influence of HDAC inhibitors on the immune response led to mixed results. In a mouse model of systemic lupus erythematosus (SLE), treatment with TSA resulted in decreased mRNA expression of several inflammatory cytokines, including IL-6, IL-12, and IFN- $\gamma$. What is interesting is that decreased mRNA expression of IL-10, which is a major anti-inflammatory cytokine, was also noted [106]. Earlier work using peripheral T cells isolated from SLE patients also showed a similar effect of decreased mRNA expression of IL-10 but an increase in IFN- $\gamma$ was also seen [107]. Two other early studies using animal models for rheumatoid arthritis have demonstrated that treatment with TSA, phenylbutyrate [46], or FK228 [45] resulted in a decrease in the proinflammatory cytokine TNF- $\alpha$. Since this initial work, numerous studies from both human and animal models of inflammatory or autoimmune diseases have documented the anti-inflammatory properties of several HDAC inhibitors [105, 115, 119-124]. While the anti-inflammatory nature of many HDAC inhibitors is well documented, this effect appears to be dose-dependent. Leoni et al. [49] documented that the dose of SAHA needed to exert its antitumor effect was much higher $(1-5 \mu \mathrm{M})$ than lower doses (50$200 \mathrm{nM}$ ) that resulted in a reduction in the production of the proinflammatory cytokines TNF- $\alpha$, IL- $1 \beta$, IFN- $\gamma$, and IL12. As reviewed in [120], several studies have corroborated that lower doses of HDAC inhibitors are anti-inflammatory, resulting in a decrease in proinflammatory cytokine production. This is not the case for all HDAC inhibitors; however, Cantley et al. [105] showed that the anti-inflammatory effects of MS-275 on human osteoclasts were only significant at the higher doses tested. These, and other studies, highlight the need for careful study design, taking into account cell type, dosage, and conservative data interpretation on the effectiveness of HDAC inhibitors as anti-inflammatory agents.

4.2. Anti-Inflammatory Uses of HDAC Inhibitors in Treatment of Chronic Inflammatory Diseases. In recent years, the use of HDAC inhibitors for the treatment of chronic inflammatory diseases has gained considerable attention. Two HDAC inhibitors (TSA and SAHA) have shown promise in future treatment for type 1 diabetes, a metabolic disease which has a substantial inflammatory component. In an in vitro study using pancreatic beta cells, both TSA and SAHA reduced cytokine-mediated cellular destruction in an NF- $\kappa$ B dependent manner, indicative of a reduction in the inflammatory pathology [125]. In other immune-related pathophysiological mechanisms, TSA has been shown to reduce production of proinflammatory cytokines and ameliorate pathological destruction of myelin in a murine model of multiple sclerosis [126-128]. However, for another HDAC inhibitor (sodium butyrate) examined in models for multiple sclerosis, increases in MMP-9 were observed, which is associated with a proinflammatory process [129]. Thus, a careful assessment of the pro- and anti-inflammatory effects of HDAC inhibitors needs to be characterized.

4.3. HDAC Inhibitor Effects on Monocytes and Macrophages. As a key regulator of immune responses, monocyte and macrophage responses to HDAC inhibitor treatment are of particular importance. Human monocytes stimulated with proinflammatory lipopolysaccharide (LPS) or TNF- $\alpha$ and subsequently treated with the novel Class I HDAC1 inhibitor NW-21 decreased synthesis of the proinflammatory cytokines MIP- $1 \alpha$ and MCP-1, suggesting that HDAC inhibitor treatment may help reduce synovial inflammation and be potentially useful in the management of rheumatoid arthritis [105]. It is interesting to note that levels of other proinflammatory cytokines, notably TNF- $\alpha$ and IL-1 $\beta$, were not affected [105] when treated with NW-21. Finally, in both in vitro and in vivo models for inflammatory bowel disease (IBD), both valproic acid and SAHA drastically reduced TNF- $\alpha$ and IFN- $\gamma$ levels, suggesting that HDAC inhibitors may prove fruitful as a novel therapy for the treatment of IBD (as reviewed in [122]).

Taken together, these studies reveal that a greater understanding of the specific cellular and molecular effects of HDAC inhibitors in mediating inflammation is sorely needed and will enhance their utility in the treatment of inflammatory diseases. These required future studies include the delineation of the pathways involved in immune modulation, either pro- or anti-inflammatory, of HDAC inhibitor treatment in a variety of experimental systems.

\section{The Power and Pleiotropy of HDAC Inhibitors as Epigenetic Regulators}

The reversible nature of epigenetic aberrations contributing to human diseases makes them desirable therapeutic targets. As such, HDAC inhibitors, which can act as epigenetic rewriters, are particularly attractive therapeutic tools. However, epigenetic processes are susceptible to both inherited and environmental conditions and are often cell-type specific, making their interpretation difficult for both researchers and clinicians alike. Furthermore, though there is certainly evidence to suggest that epigenetic aberrations may underlie many disease pathologies, there is also evidence to suggest that epigenetic changes may arise from subclinical influences (e.g., diet and age) or may be secondary to other diseases processes (e.g., inflammation), leading to the question of causality. Some illustrations of the challenges associated with the use of HDAC inhibitors as epigenetic regulators are highlighted below. 
For example, HDAC inhibitor treatment of two colon cancer cell types, HCT116 and HT29, revealed differential changes in gene expression profiles as assessed by microarray analysis [130]. Similar differential effects have also been observed in miRNA expression levels following HDAC inhibitor treatment as increases in miRNA expression have been noted in colorectal cancer and lymphoma cell lines, but no changes in miRNA levels were observed following TSA treatment of the A549 lung cancer cell line [44, 131, 132]. The differences in miRNA expression in the colorectal cell lines were methylation-dependent, while the increases in miRNA expression in lymphoma lines were dependent upon Myc acetylation and transcriptional activation [44, 131], so it is likely that pretreatment methylation and acetylation status are critical to HDAC inhibitor function.

Interestingly, the Myc-mediated control of miRNA in lymphoma cells was dependent upon cellular transformation. In untransformed cells, Myc transcriptionally activates the miR-15 and let-7a families leading to the repression of miRNA targets $\mathrm{Bcl}-2$ and $\mathrm{Bcl}-\mathrm{xL}$, triggering apoptosis, while this pathway is inactive in transformed cells [44]. However, in hematopoietic malignancies, HDACs contribute to the repression of these miRNAs by preventing Myc-dependent transcriptional activation. The use of HDAC inhibitors, specifically HDAC3 inhibitors, relieves the transcriptional repression of the miR-15 and let- 7 families, effectively triggering apoptosis and killing the cancer cells [44].

However, while apoptosis and growth inhibition are almost ubiquitously observed in all cancer cells when treated with HDAC inhibitors, other studies have shown that many cell types will also develop metastatic properties. For example, Lin et al. reported that HDAC inhibitors enhanced metastatic properties in 13 of 30 human cancer cell lines tested [133]. These cell types could be precategorized into two distinct phenotypes, but factors contributing to this undesirable HDAC inhibitor responsiveness are unclear. Intriguingly, one cell type that was unaffected by HDAC inhibitor treatment was the A549 lung cancer cell line in which miRNA expression was reported to be unchanged in response to HDAC inhibition, making it interesting to speculate as to the role of miRNA in HDAC inhibitor responsiveness.

In addition to cancer therapeutics, the successful use of HDAC inhibitors to target epigenetic dysregulation in psychiatric disorders and findings that HDAC inhibitors can function as potent anti-inflammatory agents have recently sparked much intrigue as to the possibility of using HDAC inhibitors to treat or even prevent neurodegenerative disorders as well. Additionally, evidence suggests that cognitive aging deficits are a result of disrupted epigenetic regulation and a decreased capacity to deal with inflammatory events $[134,135]$. So it was exciting when researchers demonstrated that HDAC inhibitor administration can improve ageassociated memory impairment in rodents. However, followup work revealed that neural plasticity declines with age and that treatment is ineffective in aged rodents. Furthermore, in young rodents, previous memory training had a significant influence on the effects of HDAC inhibitors on neural gene and protein expression [135] leading the authors to conclude that the effectiveness of HDAC inhibitors on neuroepigenetic control "may vary widely in association with an individual's unique history and ongoing experience [135].”

This type of scenario brings up another significant challenge in the field of epigenetic therapeutics, which is the identification of definitive epigenetic biomarkers and therapeutic targets. For example, the use of epigenome studies has shown that DNA methylation status is associated with CVD risk, but so are things like age, obesity, air pollution, and smoking, which in turn can also influence DNA methylation status [136]. Without demonstration of causality it is not possible to differentiate disease from epiphenomenon. Thus, even though candidate biomarkers have been used successfully in research settings, their utility in a clinical setting remains unclear.

\section{New HDAC Inhibitor-Based Therapeutic Approaches}

6.1. Combination Therapies with Cancer Chemotherapeutics. Hematologic malignancies have been successfully treated with HDAC inhibitors, albeit with a relatively low therapeutic efficacy. Yet, HDAC inhibitors have generally been less effective against solid tumors, with cancer progression being observed in solid tumors following HDAC inhibition. In a study to investigate why this might occur, Lin et al. observed that HDAC inhibition resulted in the development of a metastatic phenotype in $43 \%$ of the 30 human cancer cell lines tested [133]. As $90 \%$ of cancer-related mortality is the result of metastasis and invasion of tissues that are distant from the primary site, these findings warrant continued investigation [137]. Lin et al. were able to demonstrate that HDAC inhibitor-enhanced cell migration and metastasis could be suppressed by cotreatment with the protein kinase C inhibitors tamoxifen and curcumin [133]. Thus, successful treatment of solid tumors with HDAC inhibitors may require the use of combination therapies and several are currently in clinical trials (reviewed in [138]). Indeed, promising clinical outcomes have been observed in the treatment of metastatic non-small cell lung cancer when SAHA treatment was combined with carboplatin and paclitaxel, as well as in breast cancer patients when MS-275 was combined with an aromatase inhibitor $[139,140]$.

6.2. Immune and Anticancer Combination Therapies: The Melanoma Example. HDAC inhibitors have dual actions in the treatment of melanoma. Several groups have shown impaired proliferation characteristic of HDAC inhibitor treatment in melanoma cell lines $[112,114,141]$ and have gone on to demonstrate that disruption of HDAC activity resulted in altered expression of $\mathrm{MHC}$ and costimulatory molecules $[118,141]$. The subsequent increase in immunogenicity results in increased activation of $\mathrm{T}$ cells and prolonged survival in animal models $[112,114,117,118]$. Three of these groups have presented strong evidence that inhibition of HDAC6 plays a critical role in the events leading to increased activation of naïve T cells [112, 117, 141]. It should be noted that improved immunogenicity and immune surveillance are not limited to melanoma [142]. Manning et al. have shown that TSA leads 
to the reexpression of MHC Class I after upregulation of proteins involved in antigen processing and presentation in HPV 16 associated tumors [113].

However, as with other examples of the clinical uses of HDAC inhibitors, the effects of HDAC inhibition may result in opposing effects. Although abrogation of HDAC6 in macrophages and dendritic cells results in diminished production of IL-10 and induction of inflammatory APCs that activate naïve T cells [117], inhibition of HDAC11 leads to increased IL-10 production [116]. Similarly, inhibition of SIRT 1 strengthens the suppressive activity of Tregs and may be useful in enhancing Treg-based therapeutic approaches to autoimmune diseases or graft rejections [90]. In a melanoma specific example, HDAC inhibition upregulates expression of PD-1 ligand, which in and of itself would promote tolerance and decrease immune surveillance. However, this also makes cells more susceptible to immunotherapy with the anti-PD-1 receptor antibodies pembrolizumab and nivolumab [110].

\section{Conclusions}

This review has highlighted just some of the tremendous sources of variability one must consider during experimental design and selection of an HDAC inhibitor for experimental use. Typical of any inhibitor-based study, it is important to consider not just the desired class of HDAC targets, but also the concentration of the inhibitor and the type of inhibitor being investigated. However, because of the variable functions of HDAC inhibitors on multiple pathways, responses to treatment with HDAC inhibitors, including alterations in gene expression, are likely to vary not only from individual to individual, but also from cell type to cell type within an individual. Therefore, each individual patient might respond differently to treatment for a number of reasons, and the continued investigation into molecular mechanisms underlying HDAC inhibitor function is of utmost importance as the therapeutic potential of HDAC inhibitors appears to be almost unlimited.

In summary, HDAC inhibitors have been used with varying degrees of success in vitro, in vivo, and in clinical settings to treat cancer, neurodegenerative diseases, and immune disorders, and even as combinatorial approaches for antiviral therapy. However, due to the pleiotropic nature of HDAC inhibitors, modes of action, and their interactions with large numbers of proteins, it is almost certain that a single mechanism of action for a given HDAC inhibitor will never be described. Furthermore, the gene signature of the cell, as well as the cellular environment, can greatly affect the response to HDAC inhibitor treatment. Thus, as we continue to investigate the therapeutic potentials of HDAC inhibitors, it will likely be helpful to first perform comprehensive chemoproteomic profiling as the action of HDAC inhibitors should be considered in the context of the multiprotein complexes they target and not as purified catalytic subunits. Not only does this methodology allow for the identification of off-target effects, but also it supports our understanding of the function of individual HDAC inhibitors in a greater biological context in order to better predict clinical efficacy.

\section{Competing Interests}

None of the authors have conflict of interests.

\section{References}

[1] M. Fournel, C. Bonfils, Y. Hou et al., "MGCD0103, a novel isotype-selective histone deacetylase inhibitor, has broad spectrum antitumor activity in vitro and in vivo," Molecular Cancer Therapeutics, vol. 7, no. 4, pp. 759-768, 2008.

[2] D. M. Vigushin, S. Ali, P. E. Pace et al., "Trichostatin A is a histone deacetylase inhibitor with potent antitumor activity against breast cancer in vivo," Clinical Cancer Research, vol. 7, no. 4, pp. 971-976, 2001.

[3] N. Sato, T. Ohta, H. Kitagawa et al., "FR901228, a novel histone deacetylase inhibitor, induces cell cycle arrest and subsequent apoptosis in refractory human pancreatic cancer cells," International Journal of Oncology, vol. 24, no. 3, pp. 679685, 2004.

[4] H. J. Kwon, T. Owa, C. A. Hassig, J. Shimada, and S. L. Schreiber, "Depudecin induces morphological reversion of transformed fibroblasts via the inhibition of histone deacetylase," Proceedings of the National Academy of Sciences of the United States of America, vol. 95, no. 7, pp. 3356-3361, 1998.

[5] Z. R. Schoepflin, I. M. Shapiro, and M. V. Risbud, "Class I and IIa HDACs mediate HIF- $1 \alpha$ stability through PHD2-dependent mechanism, while HDAC6, a class IIb member, promotes HIF$1 \alpha$ transcriptional activity in nucleus pulposus cells of the intervertebral disc," Journal of Bone and Mineral Research, vol. 31, no. 6, pp. 1287-1299, 2016.

[6] C. F. Deroanne, K. Bonjean, S. Servotte et al., "Histone deacetylases inhibitors as anti-angiogenic agents altering vascular endothelial growth factor signaling," Oncogene, vol. 21, no. 3, pp. 427-436, 2002.

[7] A. Wassef, D. J. Watson, P. Morrison, S. Bryant, and J. Flack, "Neuroleptic-valproic acid combination in treatment of psychotic symptoms: a three-case report," Journal of Clinical Psychopharmacology, vol. 9, no. 1, pp. 45-48, 1989.

[8] M. Schroeder, M. O. Krebs, S. Bleich, and H. Frieling, "Epigenetics and depression: current challenges and new therapeutic options," Current Opinion in Psychiatry, vol. 23, no. 6, pp. 588592, 2010.

[9] M. Darvishi, T. Tiraihi, S. A. Mesbah-Namin, A. Delshad, and T. Taheri, "Decreased GFAP expression and improved functional recovery in contused spinal cord of rats following valproic acid therapy," Neurochemical Research, vol. 39, no. 12, pp. 2319-2333, 2014.

[10] J. Y. Lee, S. Maeng, S. R. Kang et al., "Valproic acid protects motor neuron death by inhibiting oxidative stress and endoplasmic reticulum stress-mediated cytochrome c release after spinal cord injury," Journal of Neurotrauma, vol. 31, no. 6, pp. 582-594, 2014.

[11] N. Khan, M. Jeffers, S. Kumar et al., "Determination of the class and isoform selectivity of small-molecule histone deacetylase inhibitors," Biochemical Journal, vol. 409, no. 2, pp. 581-589, 2008.

[12] P. Drogaris, V. Villeneuve, C. Pomiès et al., "Histone deacetylase inhibitors globally enhance $\mathrm{H} 3 / \mathrm{H} 4$ tail acetylation without affecting H3 lysine 56 acetylation," Scientific Reports, vol. 2, article 220, 2012.

[13] B. Barneda-Zahonero and M. Parra, "Histone deacetylases and cancer," Molecular Oncology, vol. 6, no. 6, pp. 579-589, 2012. 
[14] H. Liu, Q. Hu, A. J. D’Ercole, and P. Ye, "Histone deacetylase 11 regulates oligodendrocyte-specific gene expression and cell development in OL-1 oligodendroglia cells," GLIA, vol. 57, no. 1, pp. 1-12, 2009.

[15] A. Villagra, F. Cheng, H.-W. Wang et al., "The histone deacetylase HDAC11 regulates the expression of interleukin 10 and immune tolerance," Nature Immunology, vol. 10, no. 1, pp. 92100, 2009.

[16] L. Bosch-Presegué and A. Vaquero, "The dual role of sirtuins in cancer," Genes and Cancer, vol. 2, no. 6, pp. 648-662, 2011.

[17] L. R. Saunders and E. Verdin, "Sirtuins: critical regulators at the crossroads between cancer and aging," Oncogene, vol. 26, no. 37, pp. 5489-5504, 2007.

[18] M. S. Longworth and L. A. Laimins, "Histone deacetylase 3 localizes to the plasma membrane and is a substrate of Src," Oncogene, vol. 25, no. 32, pp. 4495-4500, 2006.

[19] X. Zhang, Z. Yuan, Y. Zhang et al., "HDAC6 modulates cell motility by altering the acetylation level of cortactin," Molecular Cell, vol. 27, no. 2, pp. 197-213, 2007.

[20] F. X. Soriano, S. Chawla, P. Skehel, and G. E. Hardingham, "SMRT-mediated co-shuttling enables export of class IIa HDACs independent of their CaM kinase phosphorylation sites," Journal of Neurochemistry, vol. 124, no. 1, pp. 26-35, 2013.

[21] C. Choudhary, C. Kumar, F. Gnad et al., "Lysine acetylation targets protein complexes and co-regulates major cellular functions," Science, vol. 325, no. 5942, pp. 834-840, 2009.

[22] I. V. Gregoretti, Y.-M. Lee, and H. V. Goodson, "Molecular evolution of the histone deacetylase family: functional implications of phylogenetic analysis," Journal of Molecular Biology, vol. 338, no. 1, pp. 17-31, 2004.

[23] M. A. Glozak, N. Sengupta, X. Zhang, and E. Seto, "Acetylation and deacetylation of non-histone proteins," Gene, vol. 363, pp. 15-23, 2005.

[24] M. Ocker, "Deacetylase inhibitors-focus on non-histone targets and effects," World Journal of Biological Chemistry, vol. 1, no. 5, pp. 55-61, 2010.

[25] K. Ververis, A. Hiong, T. C. Karagiannis, and P. V. Licciardi, "Histone deacetylase inhibitors (HDACIS): multitargeted anticancer agents," Biologics, vol. 7, no. 1, pp. 47-60, 2013.

[26] K. Nakane, Y. Fujita, R. Terazawa et al., "Inhibition of cortactin and SIRT1 expression attenuates migration and invasion of prostate cancer DU145 cells," International Journal of Urology, vol. 19, no. 1, pp. 71-79, 2012.

[27] B. P. Ashburner, S. D. Westerheide, and A. S. Baldwin Jr., "The p65 (RelA) subunit of NF- $\kappa$ B interacts with the histone deacetylase (HDAC) corepressors HDAC1 and HDAC2 to negatively regulate gene expression," Molecular and Cellular Biology, vol. 21, no. 20, pp. 7065-7077, 2001.

[28] J. von Burstin, S. Eser, M. C. Paul et al., "E-cadherin regulates metastasis of pancreatic cancer in vivo and is suppressed by a SNAIL/HDAC1/HDAC2 repressor complex," Gastroenterology, vol. 137, no. 1, pp. 361-371.e5, 2009.

[29] K. J. Falkenberg and R. W. Johnstone, "Histone deacetylases and their inhibitors in cancer, neurological diseases and immune disorders," Nature Reviews Drug Discovery, vol. 13, no. 9, pp. 673-691, 2014.

[30] A. C. West and R. W. Johnstone, "New and emerging HDAC inhibitors for cancer treatment," The Journal of Clinical Investigation, vol. 124, no. 1, pp. 30-39, 2014.

[31] N. Ahuja, A. R. Sharma, and S. B. Baylin, "Epigenetic therapeutics: a new weapon in the war against cancer," Annual Review of Medicine, vol. 67, no. 1, pp. 73-89, 2016.
[32] S. Yoon and G. H. Eom, "HDAC and HDAC inhibitor: from cancer to cardiovascular diseases," Chonnam Medical Journal, vol. 52, no. 1, pp. 1-11, 2016.

[33] E. Hu, E. Dul, C.-M. Sung et al., "Identification of novel isoformselective inhibitors within class I histone deacetylases," Journal of Pharmacology and Experimental Therapeutics, vol. 307, no. 2, pp. 720-728, 2003.

[34] D. Wegener, C. Hildmann, and A. Schwienhorst, "Recent progress in the development of assays suited for histone deacetylase inhibitor screening," Molecular Genetics and Metabolism, vol. 80, no. 1-2, pp. 138-147, 2003.

[35] K. Hoffmann, G. Brosch, P. Loidl, and M. Jung, "A non-isotopic assay for histone deacetylase activity," Nucleic Acids Research, vol. 27, no. 9, pp. 2057-2058, 1999.

[36] B. D. Marks, S. A. Fakhoury, W. J. Frazee, H. C. Eliason, and S. M. Riddle, "A substrate-independent TR-FRET histone deacetylase inhibitor assay," Journal of Biomolecular Screening, vol. 16, no. 10, pp. 1247-1253, 2011.

[37] D. Riester, C. Hildmann, A. Schwienhorst, and F.-J. MeyerAlmes, "Histone deacetylase inhibitor assay based on fluorescence resonance energy transfer," Analytical Biochemistry, vol. 362, no. 1, pp. 136-141, 2007.

[38] R. Furumai, A. Matsuyama, N. Kobashi et al., "FK228 (depsipeptide) as a natural prodrug that inhibits class I histone deacetylases," Cancer Research, vol. 62, no. 17, pp. 4916-4921, 2002.

[39] M. Yoshida, M. Kijima, M. Akita, and T. Beppu, "Potent and specific inhibition of mammalian histone deacetylase both in vivo and in vitro by trichostatin A," The Journal of Biological Chemistry, vol. 265, no. 28, pp. 17174-17179, 1990.

[40] T. Beckers, C. Burkhardt, H. Wieland et al., "Distinct pharmacological properties of second generation HDAC inhibitors with the benzamide or hydroxamate head group," International Journal of Cancer, vol. 121, no. 5, pp. 1138-1148, 2007.

[41] M. Ni, E. Esposito, V. P. Raj et al., "New macrocyclic analogs of the natural histone deacetylase inhibitor FK228; design, synthesis and preliminary biological evaluation," Bioorganic \& Medicinal Chemistry, vol. 23, no. 21, pp. 6785-6793, 2015.

[42] K. Saijo, T. Katoh, H. Shimodaira, A. Oda, O. Takahashi, and C. Ishioka, "Romidepsin (FK228) and its analogs directly inhibit phosphatidylinositol 3-kinase activity and potently induce apoptosis as histone deacetylase/phosphatidylinositol 3-kinase dual inhibitors," Cancer Science, vol. 103, no. 11, pp. 1994-2001, 2012.

[43] B. C. Valdez, J. E. Brammer, Y. Li et al., "Romidepsin targets multiple survival signaling pathways in malignant $\mathrm{T}$ cells," Blood Cancer Journal, vol. 5, article e357, 2015.

[44] C. M. Adams, S. W. Hiebert, and C. M. Eischen, "Myc induces miRNA-mediated apoptosis in response to HDAC inhibition in hematologic malignancies," Cancer Research, vol. 76, no. 3, pp. 736-748, 2016.

[45] K. Nishida, T. Komiyama, S.-I. Miyazawa et al., "Histone deacetylase inhibitor suppression of autoantibody-mediated arthritis in mice via regulation of p16INK4a and p21 WAF1/Cip1 expression," Arthritis and Rheumatism, vol. 50, no. 10, pp. 33653376, 2004.

[46] Y.-L. Chung, M.-Y. Lee, A.-J. Wang, and L.-F. Yao, "A therapeutic strategy uses histone deacetylase inhibitors to modulate the expression of genes involved in the pathogenesis of rheumatoid arthritis," Molecular Therapy, vol. 8, no. 5, pp. 707-717, 2003.

[47] T. Ciossek, H. Julius, H. Wieland, T. Maier, and T. Beckers, "A homogeneous cellular histone deacetylase assay suitable for 
compound profiling and robotic screening," Analytical Biochemistry, vol. 372, no. 1, pp. 72-81, 2008.

[48] M. Bantscheff, C. Hopf, M. M. Savitski et al., "Chemoproteomics profiling of HDAC inhibitors reveals selective targeting of HDAC complexes," Nature Biotechnology, vol. 29, no. 3, pp. 255265, 2011.

[49] F. Leoni, A. Zaliani, G. Bertolini et al., "The antitumor histone deacetylase inhibitor suberoylanilide hydroxamic acid exhibits antiinflammatory properties via suppression of cytokines," Proceedings of the National Academy of Sciences of the United States of America, vol. 99, no. 5, pp. 2995-3000, 2002.

[50] F. Leoni, G. Fossati, E. C. Lewis et al., “The histone deacetylase inhibitor ITF2357 reduces production of pro-inflammatory cytokines in vitro and systemic inflammation in vivo," Molecular Medicine, vol. 11, no. 1-12, pp. 1-15, 2005.

[51] T. Sanda, T. Okamoto, Y. Uchida et al., "Proteome analyses of the growth inhibitory effects of NCH-51, a novel histone deacetylase inhibitor, on lymphoid malignant cells," Leukemia, vol. 21, no. 11, pp. 2344-2353, 2007.

[52] J.-H. Cho, M. Dimri, and G. P. Dimri, "MicroRNA-31 is a transcriptional target of histone deacetylase inhibitors and a regulator of cellular senescence," Journal of Biological Chemistry, vol. 290, no. 16, pp. 10555-10567, 2015.

[53] X.-N. Li, Q. Shu, J. M.-F. Su, L. Perlaky, S. M. Blaney, and C. C. Lau, "Valproic acid induces growth arrest, apoptosis, and senescence in medulloblastomas by increasing histone hyperacetylation and regulating expression of p21Cip1, CDK4, and CMYC," Molecular Cancer Therapeutics, vol. 4, no. 12, pp. 1912-1922, 2005.

[54] Y. Zhai, X. Chen, D. Yu et al., "Histone deacetylase inhibitor valproic acid promotes the induction of pluripotency in mouse fibroblasts by suppressing reprogramming-induced senescence stress," Experimental Cell Research, vol. 337, no. 1, pp. 61-67, 2015.

[55] M. Malvaez, S. C. McQuown, G. A. Rogge et al., "HDAC3selective inhibitor enhances extinction of cocaine-seeking behavior in a persistent manner," Proceedings of the National Academy of Sciences of the United States of America, vol. 110, no. 7, pp. 2647-2652, 2013.

[56] F. Santoro, O. A. Botrugno, R. Dal Zuffo et al., "A dual role for Hdacl: oncosuppressor in tumorigenesis, oncogene in tumor maintenance," Blood, vol. 121, no. 17, pp. 3459-3468, 2013.

[57] Y. Komatsu, K. Tomizaki, M. Tsukamoto et al., "Cyclic hydroxamic-acid-containing peptide 31, a potent synthetic histone deacetylase inhibitor with antitumor activity," Cancer Research, vol. 61, no. 11, pp. 4459-4466, 2001.

[58] R. Soriano-Cantón, A. Perez-Villalba, J. M. Morante-Redolat et al., "Regulation of the $\mathrm{p} 19^{\mathrm{Arf}} / \mathrm{p} 53$ pathway by histone acetylation underlies neural stem cell behavior in senescence-prone SAMP8 mice," Aging Cell, vol. 14, no. 3, pp. 453-462, 2015.

[59] F. Li, R. Wu, X. Cui et al., "Histone deacetylase 1 (HDAC1) negatively regulates thermogenic program in brown adipocytes via coordinated regulation of histone $\mathrm{H} 3$ lysine 27 (H3K27) deacetylation and methylation," The Journal of Biological Chemistry, vol. 291, no. 9, pp. 4523-4536, 2016.

[60] K. Saijo, J. Imamura, K. Narita et al., "Biochemical, biological and structural properties of romidepsin (FK228) and its analogs as novel HDAC/PI3K dual inhibitors," Cancer Science, vol. 106, no. 2, pp. 208-215, 2015.

[61] K. Sugita, H. Yoshida, M. Matsumoto, and S. Matsutani, "A novel compound, depudecin, induces production of transformation to the flat phenotype of NIH3T3 cells transformed by rasoncogene," Biochemical and Biophysical Research Communications, vol. 182, no. 1, pp. 379-387, 1992.

[62] C. Choudhary, B. T. Weinert, Y. Nishida, E. Verdin, and M. Mann, "The growing landscape of lysine acetylation links metabolism and cell signalling," Nature Reviews Molecular Cell Biology, vol. 15, no. 8, pp. 536-550, 2014.

[63] M. R. Davis, J. J. Daggett, A. S. Pascual et al., "Epigenetically maintained SW13+ and SW13- subtypes have different oncogenic potential and convert with HDAC1 inhibition," BMC Cancer, vol. 16, no. 1, pp. 1-13, 2016.

[64] P.-H. Huang, C.-H. Chen, C.-C. Chou et al., "Histone deacetylase inhibitors stimulate histone $\mathrm{H} 3$ lysine 4 methylation in part via transcriptional repression of histone $\mathrm{H} 3$ lysine 4 demethylases," Molecular Pharmacology, vol. 79, no. 1, pp. 197206, 2011.

[65] J. A. Halsall, N. Turan, M. Wiersma, and B. M. Turner, "Cells adapt to the epigenomic disruption caused by histone deacetylase inhibitors through a coordinated, chromatin-mediated transcriptional response," Epigenetics and Chromatin, vol. 8, article 29, 2015.

[66] W. Gu and R. G. Roeder, "Activation of p53 sequence-specific DNA binding by acetylation of the p53 C-terminal domain," Cell, vol. 90, no. 4, pp. 595-606, 1997.

[67] J. Luo, M. Li, Y. Tang, M. Laszkowska, R. G. Roeder, and W. $\mathrm{Gu}$, "Acetylation of p53 augments its site-specific DNA binding both in vitro and in vivo," Proceedings of the National Academy of Sciences of the United States of America, vol. 101, no. 8, pp. 2259-2264, 2004.

[68] Y. Xu, "Regulation of p53 responses by post-translational modifications," Cell Death and Differentiation, vol. 10, no. 4, pp. 400-403, 2003.

[69] A. Ito, Y. Kawaguchi, C.-H. Lai et al., "MDM2-HDAC1mediated deacetylation of p53 is required for its degradation," The EMBO Journal, vol. 21, no. 22, pp. 6236-6245, 2002.

[70] Y.-H. Jin, E.-J. Jeon, Q.-L. Li et al., "Transforming growth factor- $\beta$ stimulates p300-dependent RUNX3 acetylation, which inhibits ubiquitination-mediated degradation," Journal of Biological Chemistry, vol. 279, no. 28, pp. 29409-29417, 2004.

[71] Z.-L. Yuan, Y.-J. Guan, D. Chatterjee, and Y. E. Chin, "Stat3 dimerization regulated by reversible acetylation of a single lysine residue," Science, vol. 307, no. 5707, pp. 269-273, 2005.

[72] R. Wang, P. Cherukuri, and J. Luo, "Activation of Stat3 sequencespecific DNA binding and transcription by p300/CREBbinding protein-mediated acetylation," The Journal of Biological Chemistry, vol. 280, no. 12, pp. 11528-11534, 2005.

[73] Y. Li, X. Zhang, R. D. Polakiewicz, T.-P. Yao, and M. J. Comb, "HDAC6 is required for epidermal growth factor-induced $\beta$ catenin nuclear localization," The Journal of Biological Chemistry, vol. 283, no. 19, pp. 12686-12690, 2008.

[74] C. Wang, M. Fu, R. H. Angeletti et al., "Direct acetylation of the estrogen receptor $\alpha$ hinge region by p300 regulates transactivation and hormone sensitivity," Journal of Biological Chemistry, vol. 276, no. 21, pp. 18375-18383, 2001.

[75] H. Kawai, H. Li, S. Avraham, S. Jiang, and H. K. Avraham, "Overexpression of histone deacetylase HDAC1 modulates breast cancer progression by negative regulation of estrogen receptor $\alpha$, International Journal of Cancer, vol. 107, no. 3, pp. 353-358, 2003.

[76] J. H. Patel, Y. Du, P. G. Ard et al., "The c-MYC oncoprotein is a substrate of the acetyltransferases hGCN5/PCAF and TIP60," 
Molecular and Cellular Biology, vol. 24, no. 24, pp. 10826-10834, 2004.

[77] S. E. Salghetti, M. Muratani, H. Wijnen, B. Futcher, and W. P. Tansey, "Functional overlap of sequences that activate transcription and signal ubiquitin-mediated proteolysis," Proceedings of the National Academy of Sciences of the United States of America, vol. 97, no. 7, pp. 3118-3123, 2000.

[78] W. Zhang, S. Kadam, B. M. Emerson, and J. J. Bieker, "Sitespecific acetylation by $\mathrm{p} 300$ or CREB binding protein regulates erythroid Krüppel-like factor transcriptional activity via its interaction with the SWI-SNF complex," Molecular and Cellular Biology, vol. 21, no. 7, pp. 2413-2422, 2001.

[79] W. Zhang and J. J. Bieker, "Acetylation and modulation of erythroid Krüppel-like factor (EKLF) activity by interaction with histone acetyltransferases," Proceedings of the National Academy of Sciences of the United States of America, vol. 95, no. 17, pp. 9855-9860, 1998.

[80] M. A. Martínez-Balbás, U.-M. Bauer, S. J. Nielsen, A. Brehm, and T. Kouzarides, "Regulation of E2F1 activity by acetylation," The EMBO Journal, vol. 19, no. 4, pp. 662-671, 2000.

[81] G. Marzio, C. Wagener, M. I. Gutierrez, P. Cartwright, K. Helin, and M. Giacca, "E2F family members are differentially regulated by reversible acetylation," The Journal of Biological Chemistry, vol. 275, no. 15, pp. 10887-10892, 2000.

[82] J. Boyes, P. Byfield, Y. Nakatani, and V. Ogryzko, "Regulation of activity of the transcription factor GATA-1 by acetylation," Nature, vol. 396, no. 6711, pp. 594-598, 1998.

[83] F. Hayakawa, M. Towatari, Y. Ozawa, A. Tomita, M. L. Privalsky, and H. Saito, "Functional regulation of GATA-2 by acetylation," Journal of Leukocyte Biology, vol. 75, no. 3, pp. 529-540, 2004.

[84] T. Yamagata, K. Mitani, H. Oda et al., "Acetylation of GATA3 affects T-cell survival and homing to secondary lymphoid organs," The EMBO Journal, vol. 19, no. 17, pp. 4676-4687, 2000.

[85] J.-W. Jeong, M.-K. Bae, M.-Y. Ahn et al., "Regulation and destabilization of HIF-1 $\alpha$ by ARD1-mediated acetylation," Cell, vol. 111, no. 5, pp. 709-720, 2002.

[86] V. Sartorelli, P. L. Puri, Y. Hamamori et al., "Acetylation of MyoD directed by PCAF is necessary for the execution of the muscle program," Molecular Cell, vol. 4, no. 5, pp. 725-734, 1999.

[87] A. Polesskaya and A. Harel-Bellan, "Acetylation of MyoD by p300 requires more than its histone acetyltransferase domain," The Journal of Biological Chemistry, vol. 276, no. 48, pp. 4450244503, 2001.

[88] A. Polesskaya, A. Duquet, I. Naguibneva et al., "CREB-binding protein/p300 activates MyoD by acetylation," The Journal of Biological Chemistry, vol. 275, no. 44, pp. 34359-34364, 2000.

[89] L.-F. Chen, W. Fischle, E. Verdin, and W. C. Greene, "Duration of nuclear NF- $\kappa \mathrm{B}$ action regulated by reversible acetylation," Science, vol. 293, no. 5535, pp. 1653-1657, 2001.

[90] H.-S. Kwon, H. W. Lim, J. Wu, M. Schnölzer, E. Verdin, and M. Ott, "Three novel acetylation sites in the Foxp3 transcription factor regulate the suppressive activity of regulatory T cells," Journal of Immunology, vol. 188, no. 6, pp. 2712-2721, 2012.

[91] Q. Cao, J. Yu, S. M. Dhanasekaran et al., "Repression of Ecadherin by the polycomb group protein EZH2 in cancer," Oncogene, vol. 27, no. 58, pp. 7274-7284, 2008.

[92] S. Glaros, G. M. Cirrincione, C. Muchardt, C. G. Kleer, C. W. Michael, and D. Reisman, "The reversible epigenetic silencing of BRM: implications for clinical targeted therapy," Oncogene, vol. 26, no. 49, pp. 7058-7066, 2007.
[93] N. Yamamichi, M. Yamamichi-Nishina, T. Mizutani et al., "The Brm gene suppressed at the post-transcriptional level in various human cell lines is inducible by transient HDAC inhibitor treatment, which exhibits antioncogenic potential," Oncogene, vol. 24, no. 35, pp. 5471-5481, 2005.

[94] C. Kadoch, D. C. Hargreaves, C. Hodges et al., "Proteomic and bioinformatic analysis of mammalian SWI/SNF complexes identifies extensive roles in human malignancy," Nature Genetics, vol. 45, no. 6, pp. 592-601, 2013.

[95] Y. Y. Sanders, T. O. Tollefsbol, B. M. Varisco, and J. S. Hagood, "Epigenetic regulation of Thy-1 by histone deacetylase inhibitor in rat lung fibroblasts," American Journal of Respiratory Cell and Molecular Biology, vol. 45, no. 1, pp. 16-23, 2011.

[96] H. Jia, C. D. Morris, R. M. Williams, J. F. Loring, and E. A. Thomas, "HDAC inhibition imparts beneficial transgenerational effects in Huntington's disease mice via altered DNA and histone methylation," Proceedings of the National Academy of Sciences of the United States of America, vol. 112, no. 1, pp. E56E64, 2015.

[97] T. Wada, J. Kikuchi, and Y. Furukawa, "Histone deacetylase 1 enhances microRNA processing via deacetylation of DGCR8," EMBO Reports, vol. 13, no. 2, pp. 142-149, 2012.

[98] E. J. Noonan, R. F. Place, D. Pookot et al., "MiR-449a targets HDAC-1 and induces growth arrest in prostate cancer," Oncogene, vol. 28, no. 14, pp. 1714-1724, 2009.

[99] H. J. Bae, K. H. Jung, J. W. Eun et al., "MicroRNA-221 governs tumor suppressor HDAC6 to potentiate malignant progression of liver cancer," Journal of Hepatology, vol. 63, no. 2, pp. 408-419, 2015.

[100] T. Qiu, L. Zhou, W. Zhu et al., "Effects of treatment with histone deacetylase inhibitors in solid tumors: a review based on 30 clinical trials," Future Oncology, vol. 9, no. 2, pp. 255-269, 2013.

[101] M. Slingerland, H.-J. Guchelaar, and H. Gelderblom, "Histone deacetylase inhibitors: an overview of the clinical studies in solid tumors," Anti-Cancer Drugs, vol. 25, no. 2, pp. 140-149, 2014.

[102] N. Ahuja, H. Easwaran, and S. B. Baylin, "Harnessing the potential of epigenetic therapy to target solid tumors," The Journal of Clinical Investigation, vol. 124, no. 1, pp. 56-63, 2014.

[103] L. Andresen, H. Jensen, M. T. Pedersen, K. A. Hansen, and S. Skov, "Molecular regulation of MHC class I chain-related protein A expression after HDAC-inhibitor treatment of jurkat T cells," The Journal of Immunology, vol. 179, no. 12, pp. 8235-8242, 2007.

[104] J. S. Waby, H. Chirakkal, C. Yu et al., "Sp1 acetylation is associated with loss of DNA binding at promoters associated with cell cycle arrest and cell death in a colon cell line," Molecular Cancer, vol. 9, article 275, 2010.

[105] M. D. Cantley, D. P. Fairlie, P. M. Bartold, V. Marino, P. K. Gupta, and D. R. Haynes, "Inhibiting histone deacetylase 1 suppresses both inflammation and bone loss in arthritis," Rheumatology, vol. 54, no. 9, pp. 1713-1723, 2015.

[106] N. Mishra, C. M. Reilly, D. R. Brown, P. Ruiz, and G. S. Gilkeson, "Histone deacetylase inhibitors modulate renal disease in the MRL-lpr/lpr mouse," The Journal of Clinical Investigation, vol. 111, no. 4, pp. 539-552, 2003.

[107] N. Mishra, D. R. Brown, I. M. Olorenshaw, and G. M. Kammer, "Trichostatin A reverses skewed expression of CD154, interleukin-10, and interferon- $\gamma$ gene and protein expression in lupus T cells," Proceedings of the National Academy of Sciences of the United States of America, vol. 98, no. 5, pp. 2628-2633, 2001. 
[108] X. Wu, Y. Tao, J. Hou, X. Meng, and J. Shi, "Valproic acid upregulates NKG2D ligand expression through an ERK-dependent mechanism and potentially enhances NK cell-mediated lysis of myeloma," Neoplasia, vol. 14, no. 12, pp. 1178-1189, 2012.

[109] S. Armeanu, M. Bitzer, U. M. Lauer et al., "Natural killer cell-mediated lysis of hepatoma cells via specific induction of NKG2D ligands by the histone deacetylase inhibitor sodium valproate," Cancer Research, vol. 65, no. 14, pp. 6321-6329, 2005.

[110] D. M. Woods, A. L. Sodre, A. Villagra, A. Sarnaik, E. M. Sotomayor, and J. Weber, "HDAC inhibition upregulates PD-1 ligands in melanoma and augments immunotherapy with PD-1 blockade," Cancer Immunology Research, vol. 3, no. 12, pp. 13751385, 2015.

[111] S. Skov, M. T. Pedersen, L. Andresen, P. T. Straten, A. Woetmann, and N. Ødum, "Cancer cells become susceptible to natural killer cell killing after exposure to histone deacetylase inhibitors due to glycogen synthase kinase-3-dependent expression of MHC class I-related chain A and B," Cancer Research, vol. 65, no. 23, pp. 11136-11145, 2005.

[112] K. V. Woan, M. Lienlaf, P. Perez-Villaroel et al., "Targeting histone deacetylase 6 mediates a dual anti-melanoma effect: enhanced antitumor immunity and impaired cell proliferation," Molecular Oncology, vol. 9, no. 7, pp. 1447-1457, 2015.

[113] J. Manning, M. Indrova, B. Lubyova et al., "Induction of MHC class I molecule cell surface expression and epigenetic activation of antigen-processing machinery components in a murine model for human papilloma virus 16-associated tumours," Immunology, vol. 123, no. 2, pp. 218-227, 2008.

[114] D. M. Woods, K. Woan, F. Cheng et al., "The antimelanoma activity of the histone deacetylase inhibitor panobinostat (LBH589) is mediated by direct tumor cytotoxicity and increased tumor immunogenicity," Melanoma Research, vol. 23, no. 5, pp. 341-348, 2013.

[115] R. Di Liddo, S. Valente, S. Taurone et al., "Histone deacetylase inhibitors restore IL-10 expression in lipopolysaccharideinduced cell inflammation and reduce IL- $1 \beta$ and IL- 6 production in breast silicone implant in C57BL/6J wild-type murine model," Autoimmunity, 2016.

[116] F. Cheng, M. Lienlaf, P. Perez-Villarroel et al., "Divergent roles of histone deacetylase 6 (HDAC6) and histone deacetylase 11 (HDAC11) on the transcriptional regulation of IL10 in antigen presenting cells," Molecular Immunology, vol. 60, no. 1, pp. 4453, 2014.

[117] F. Cheng, M. Lienlaf, H.-W. Wang et al., "A novel role for histone deacetylase 6 in the regulation of the tolerogenic STAT3/IL-10 pathway in APCs," Journal of Immunology, vol. 193, no. 6, pp. 2850-2862, 2014.

[118] A. F. Setiadi, K. Omilusik, M. D. David et al., "Epigenetic enhancement of antigen processing and presentation promotes immune recognition of tumors," Cancer Research, vol. 68, no. 23, pp. 9601-9607, 2008.

[119] I. M. Adcock, "HDAC inhibitors as anti-inflammatory agents," British Journal of Pharmacology, vol. 150, no. 7, pp. 829-831, 2007.

[120] C. A. Dinarello, "Anti-inflammatory agents: present and future," Cell, vol. 140, no. 6, pp. 935-950, 2010.

[121] C. A. Dinarello, G. Fossati, and P. Mascagni, "Histone deacetylase inhibitors for treating a spectrum of diseases not related to cancer," Molecular Medicine, vol. 17, no. 5-6, pp. 333-352, 2011.

[122] A. J. P. Edwards and S. L. F. Pender, "Histone deacetylase inhibitors and their potential role in inflammatory bowel diseases," Biochemical Society Transactions, vol. 39, no. 4, pp. 1092-1095, 2011.

[123] W. W. Hancock, T. Akimova, U. H. Beier, Y. Liu, and L. Wang, "HDAC inhibitor therapy in autoimmunity and transplantation," Annals of the Rheumatic Diseases, vol. 71, supplement 2, pp. i46-i54, 2012.

[124] B. W. Bridle, L. Chen, C. G. Lemay et al., "HDAC inhibition suppresses primary immune responses, enhances secondary immune responses, and abrogates autoimmunity during tumor immunotherapy," Molecular Therapy, vol. 21, no. 4, pp. 887-894, 2013.

[125] L. Larsen, M. Tonnesen, S. G. Ronn et al., "Inhibition of histone deacetylases prevents cytokine-induced toxicity in beta cells," Diabetologia, vol. 50, no. 4, pp. 779-789, 2007.

[126] S. J. Shuttleworth, S. G. Bailey, and P. A. Townsend, "Histone Deacetylase inhibitors: new promise in the treatment of immune and inflammatory diseases," Current Drug Targets, vol. 11, no. 11, pp. 1430-1438, 2010.

[127] G. Faraco, L. Cavone, and A. Chiarugi, "The therapeutic potential of HDAC inhibitors in the treatment of multiple sclerosis," Molecular Medicine, vol. 17, no. 5-6, pp. 442-447, 2011.

[128] S. Camelo, A. H. Iglesias, D. Hwang et al., "Transcriptional therapy with the histone deacetylase inhibitor trichostatin A ameliorates experimental autoimmune encephalomyelitis," Journal of Neuroimmunology, vol. 164, no. 1-2, pp. 10-21, 2005.

[129] A. S. Fiorino and I. Zvibel, "Disruption of cell-cell adhesion in the presence of sodium butyrate activates expression of the $92 \mathrm{kDa}$ type IV collagenase in MDCK cells," Cell Biology International, vol. 20, no. 7, pp. 489-499, 1996.

[130] M. J. LaBonte, P. M. Wilson, W. Fazzone, S. Groshen, H.-J. Lenz, and R. D. Ladner, "DNA microarray profiling of genes differentially regulated by the histone deacetylase inhibitors vorinostat and LBH589 in colon cancer cell lines," BMC Medical Genomics, vol. 2, article 67, 2009.

[131] E. Bandres, X. Agirre, N. Bitarte et al., "Epigenetic regulation of microRNA expression in colorectal cancer," International Journal of Cancer, vol. 125, no. 11, pp. 2737-2743, 2009.

[132] S. Diederichs and D. A. Haber, "Sequence variations of microRNAs in human cancer: alterations in predicted secondary structure do not affect processing," Cancer Research, vol. 66, no. 12, pp. 6097-6104, 2006.

[133] K.-T. Lin, Y.-W. Wang, C.-T. Chen, C.-M. Ho, W.-H. Su, and Y.$\mathrm{S}$. Jou, "HDAC inhibitors augmented cell migration and metastasis through induction of PKCs leading to identification of low toxicity modalities for combination cancer therapy," Clinical Cancer Research, vol. 18, no. 17, pp. 4691-4701, 2012.

[134] E. Benito, H. Urbanke, B. Ramachandran et al., "HDAC inhibitor-dependent transcriptome and memory reinstatement in cognitive decline models," Journal of Clinical Investigation, vol. 125, no. 9, pp. 3572-3584, 2015.

[135] A. S. Sewal, H. Patzke, E. J. Perez et al., "Experience modulates the effects of histone deacetylase inhibitors on gene and protein expression in the hippocampus: impaired plasticity in aging," The Journal of Neuroscience, vol. 35, no. 33, pp. 11729-11742, 2015.

[136] S. Aslibekyan, E. W. Demerath, M. Mendelson et al., "Epigenome-wide study identifies novel methylation loci associated with body mass index and waist circumference," Obesity, vol. 23, no. 7, pp. 1493-1501, 2015.

[137] S. Keleg, P. Büchler, R. Ludwig, M. W. Büchler, and H. Friess, "Invasion and metastasis in pancreatic cancer," Molecular Cancer, vol. 2, article 14, 2003. 
[138] L. Robert, A. Ribas, and S. Hu-Lieskovan, "Combining targeted therapy with immunotherapy. Can $1+1$ equal more than 2?" Seminars in Immunology, vol. 28, no. 1, pp. 73-80, 2016.

[139] S. S. Ramalingam, M. L. Maitland, P. Frankel et al., "Carboplatin and paclitaxel in combination with either vorinostat or placebo for first-line therapy of advanced non-small-cell lung cancer," Journal of Clinical Oncology, vol. 28, no. 1, pp. 56-62, 2010.

[140] D. A. Yardley, R. R. Ismail-Khan, B. Melichar et al., "Randomized phase II, double-blind, placebo-controlled study of exemestane with or without entinostat in postmenopausal women with locally recurrent or metastatic estrogen receptorpositive breast cancer progressing on treatment with a nonsteroidal aromatase inhibitor," Journal of Clinical Oncology, vol. 31, no. 17, pp. 2128-2135, 2013.

[141] M. Balliu, L. Guandalini, M. N. Romanelli, M. D’Amico, and F. Paoletti, "HDAC-inhibitor (S)-8 disrupts HDAC6-PP1 complex prompting A375 melanoma cell growth arrest and apoptosis," Journal of Cellular and Molecular Medicine, vol. 19, no. 1, pp. 143154, 2015.

[142] L. Shen, A. Orillion, and R. Pili, "Histone deacetylase inhibitors as immunomodulators in cancer therapeutics," Epigenomics, vol. 8, no. 3, pp. 415-428, 2016. 

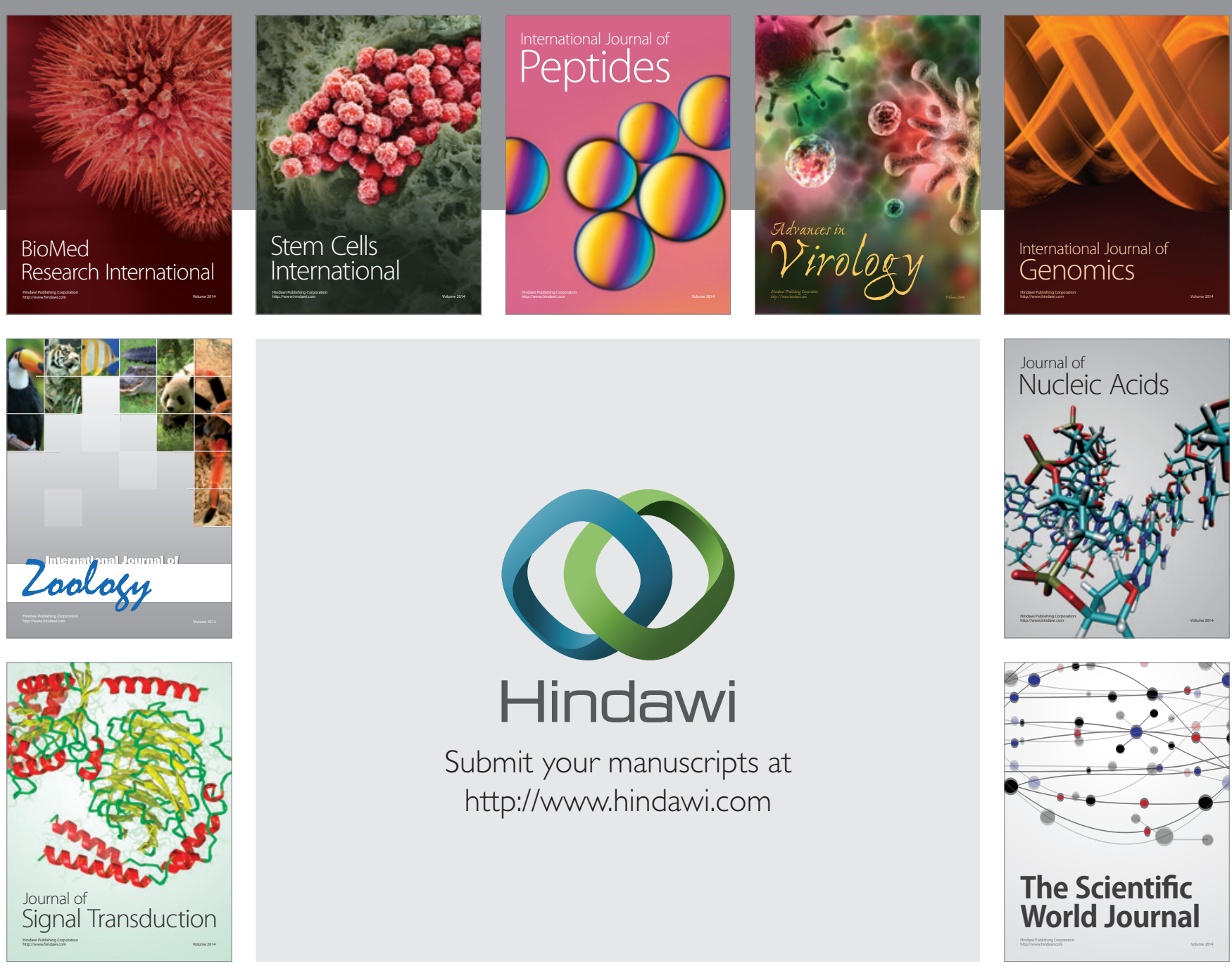

Submit your manuscripts at

http://www.hindawi.com
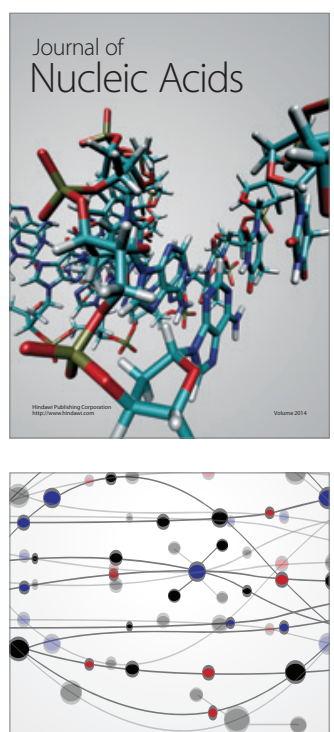

The Scientific World Journal
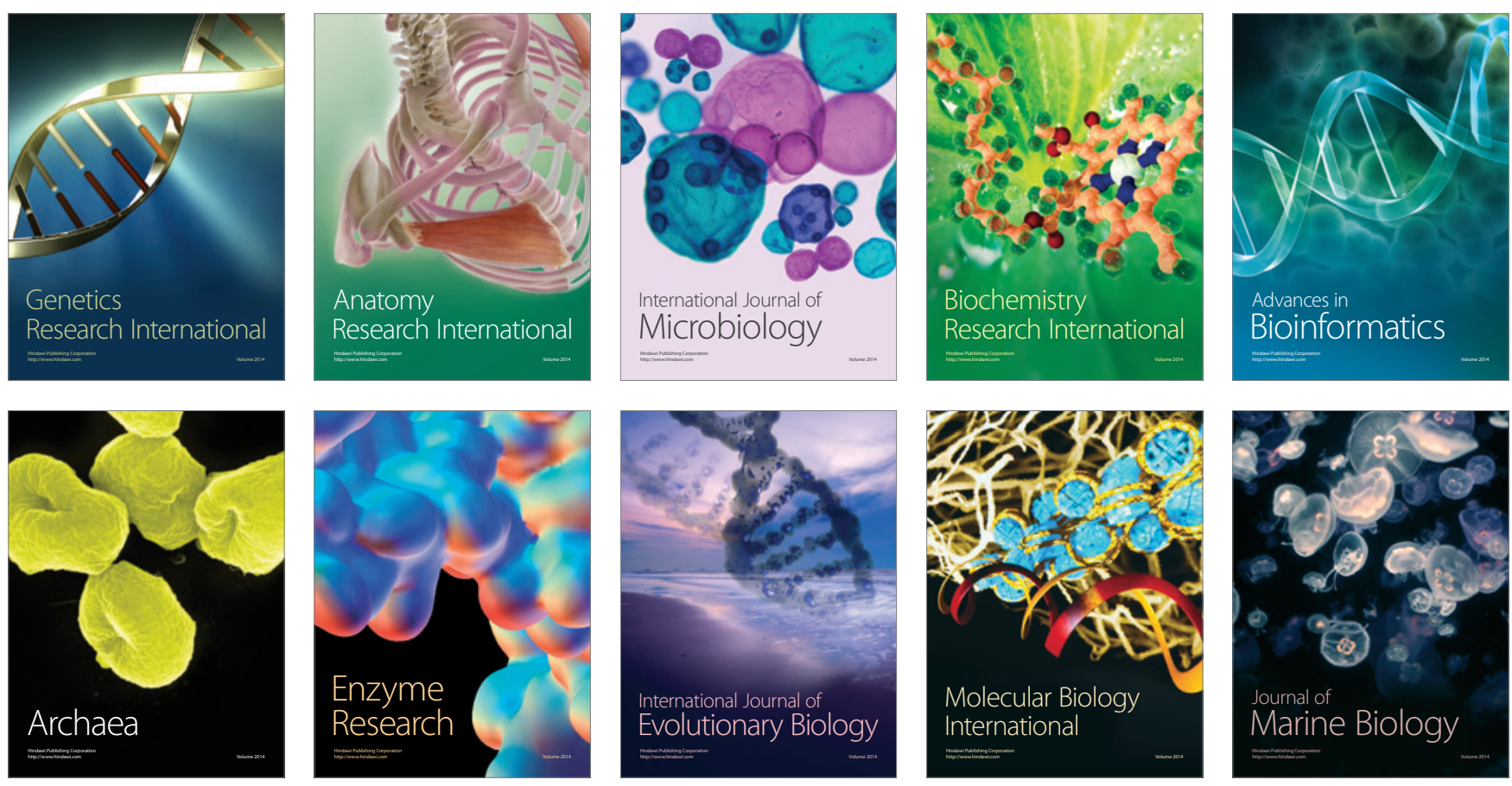